Article

\title{
Sustainable and Smart Manufacturing: An Integrated Approach
}

\author{
Mohamed Abubakr ${ }^{1}\left(\right.$, Adel T. Abbas ${ }^{2, *}$, Italo Tomaz ${ }^{3}{ }^{\circledR}$, Mahmoud S. Soliman ${ }^{2}$, \\ Monis Luqman ${ }^{2}$ and Hussien Hegab ${ }^{1}$ \\ 1 Mechanical Design and Production Engineering Department, Cairo University, Giza 12613, Egypt; \\ m.abobaker@live.com (M.A.); hussien.hegab@uoit.ca (H.H.) \\ 2 Department of Mechanical Engineering, College of Engineering, King Saud University, Riyadh 11421, \\ Saudi Arabia; solimanm@ksu.edu.sa (M.S.S.); monisluqman9@gmail.com (M.L.) \\ 3 Laboratório de Ensaios dos Materiais, Instituto Federal Fluminense, Cabo Frio 28909-971, Brazil; \\ italo.tomaz@iff.edu.br \\ * Correspondence: aabbas@ksu.edu.sa
}

Received: 18 January 2020; Accepted: 7 March 2020; Published: 14 March 2020

check for updates

\begin{abstract}
The necessity for decreasing the negative impact of the manufacturing industry has recently increased. This is getting recognized as a global challenge due to the rapid increase in life quality standards, demand, and the decrease in available resources. Thus, manufacturing, as a core of the product provision system and a fundamental pillar of civilized existence, is significantly influenced by sustainability issues. Furthermore, current manufacturing modeling and assessment criteria require intensive revisions and upgrades to keep up with these new challenges. Nearly all current manufacturing models are based on the old paradigm, which was proven to be inadequate. Therefore, manufacturing technology, along with culture and economy, are held responsible for providing new tools and opportunities for building novel resolutions towards a sustainable manufacturing concept. One of such tools is sustainability assessment measures. Revising and updating such tools is a core responsibility of the manufacturing sector to efficiently evaluate and enhance sustainable manufacturing performance. These measures should be adequate to respond to the growing sustainability concerns in pursuit of an integrated sustainability concept. The triple bottom line (TBL) that includes environment, economic, and social dimensions has usually been used to evaluate sustainability. However, there is a lack of standard sets of sustainable manufacturing performance measures. In addition to the sustainability concept, a new concept of smart manufacturing is emerging. The smart manufacturing concept takes advantage of the recent technological leap in Artificial Intelligent (AI), Cloud Computing (CC), and the Internet of Things (IoT). Although this concept offers an important step to boost the current production capabilities to meet the growing need, it is still not clear whether the two concepts of smart manufacturing and sustainability will constructively or destructively interact. Therefore, the current study aims to integrate the sustainable smart manufacturing performance by incorporating sustainable manufacturing measures and discussing current and future challenges that are faced by the manufacturing sector. In addition, the opportunities for future research incorporating sustainable smart manufacturing are also presented.
\end{abstract}

Keywords: sustainability; smart manufacturing; challenges; assessment; opportunities

\section{Introduction}

The "sustainable manufacturing" concept refers to all industrial activities from the factory to the customer including all in-between steps (i.e., resources and services that are connected to the manufacturing chain). In modern society, manufacturing is connected to all human activities, and it 
is a source of products and services that are necessary for human health, safety and well-being [1]. Considering that manufacturing processes are responsible for the production of essential products to improve the quality of human life and the global economy, it is vital to analyze it from the sustainability point of view. In order to fully understand the "sustainable manufacturing" concept, it is necessary to define and clarify the approach objectives, implementation steps, as well as assessment techniques, as previously presented in open literature [2,3]. Since the manufacturing stage is a part of the product's supply chain, which consumes more energy and resources, implementation of the "design of manufacturing" approach is an important key to achieve sustainability goals. Furthermore, when taking the full perspective of sustainability in consideration, sustainable manufacturing can be an essential strategy to promote better financial performance and satisfy social and environmental objectives and regulations [4].

Over the last decades, sustainable lifecycle design (SLD) has shown substantial growth and has become one of the focal areas in many engineering and industrial applications [5]. However, there still is a gap between the theory and practice when it comes to holistically integrating sustainability. Despite growing attention to sustainable development, more efforts are still needed to overcome the economic, environmental, and social challenges [6-8]. Also, there is a need to establish a framework for both practitioners and scholars when it comes to sustainable manufacturing, as many industries seem to not be mindful of the potential benefits of the sustainable manufacturing approach. Therefore, in the present work, a new and comprehensive study is presented to discuss and highlight the following points:

1. The concepts and benefits/opportunities associated with the proper implementation of sustainable manufacturing. The accurate identification of these opportunities paves the road for establishing a sustainable smart manufacturing (SSM) approach for different manufacturing industries;

2. The challenges facing the current industries to establish the SSM approach.

This article is divided into the following main sections. In Section 2, the sustainability concept is reviewed from the manufacturing point of view. This section aims to discuss the sustainability principle, assessment, and possible opportunities. Then in Section 3, smart manufacturing and the fourth industrial revolution are discussed, and a novel business model integrating factory 4.0 with sustainability is proposed. During this section, the impact of applying factory 4.0 on each of the TBL sustainability directions are highlighted. Finally, in Section 4, the main challenges of the integrated factory 4.0 and sustainability approach are presented. It should be stated that this work offers the first attempt in the literature to analyze the opportunities created by industry 4.0 from the sustainable manufacturing point of view and identify the challenges related to the practical implementation of such a new approach.

\section{Sustainable Manufacturing: Concepts and Opportunities}

Sustainable manufacturing is based on the $6 \mathrm{R}$ (i.e., reduce, redesign, reuse, recover, remanufacture, and recycle) instead of the $3 R$ approach (i.e., reduce, reuse, and recycle) [9]. In the $6 \mathrm{R}$ methodology, "reduce" refers to reducing the efforts of using the resources and energy consumption during manufacturing, resulting in lower waste during the usage stage. The "reuse" perspective is connected to the reuse of the products or the previously manufactured parts after its first lifecycle, which contributes to reducing resource consumption. "Recycle" is the process of reusing the used materials that are typically considered as waste into new materials or products. Regarding the "Recover", it occurs when components are collected at the end of the first lifecycle and then disassembled, cleaned, and prepared for the next lifecycle. The act of "Redesign" consists of using methods such as Design for Environment (DfE), to redesign the merchandise to make it further maintainable [10]. In terms of the "remanufacture", it includes the reusing of a previously used product, restoring it to initial state through the recycling of as many parts as likely without loss of operation [11,12]. Many efforts have been made to develop models for implementing sustainability in the manufacturing industry. 
Recently, various outlines for maintainable manufacturing, production, supply chains $[13,14]$, and sustainable modeling-optimization tools have been developed $[9,15,16]$. Despite these models and frameworks, it is still necessary for manufacturing engineers and designers to recognize the importance of developing sustainable processes and products. To effectively integrate the sustainability concept into manufacturing, a lasting commitment over the complete design procedure is required, as discussed in the open literature $[17,18]$. Sustainability in the manufacturing industry can be addressed through three phases [2,3]:

- Research: requirements for early evaluation of explicit sustainability such as pollution, energy, and resource usage. Research should predict and avoid possible sustainability issues during the product lifecycle;

- Development: environmental performance improvement with a focus on appropriate apparatus assortment and system design using suitable systems and methods;

- Commercialization: collaboration among the customers, suppliers, and vendors to identify possible problems in product lifecycle and improve it when it is required.

New manufacturing technologies are also contributing to achieving reliable, sustainable processes. Additive forming technologies can be used as an example of manufacturing processes that, for many years, have been used only for rapid prototyping. Although, now, metal additive forming is opening the doors to manufacturing various components by additive manufacturing. Additive manufacturing reduces the number of manufacturing steps resulting in a considerable reduction in waste and energy consumption. Another example of the contribution of new technologies in sustainable manufacturing is laser-assisted machining, which is known to extend the tool life. It is also known to improve the surface durability against wear and thus to extend the product life. The advancement in the use of these techniques and other techniques such as minimum quantity lubricant (MQL) will promote efficient large-scale manufacturing, contributing to both environmental impact and business profitability.

It is essential to define the sustainable manufacturing concept before showing the opportunities and benefits of implementing such an approach. Sustainable manufacturing differs from regular manufacturing concepts because it considers the triple bottom line (TBL) assessment criteria, which simultaneously considers the environment, economic, and social dimensions. The TBL is an assessment tool introduced by John Elkington in the mid-1900s, which was the first measure to simultaneously quantify the extent to which sustainability aspects are adopted, which was not possible by conventional methods at that time. The adaptation of this approach alters both the design and assessment process from an economic-oriented process to a holistically broader process. Manufacturing processes designed for sustainability do not consider the economic pillar as the only perspective to be optimized, but they also keep in mind the environmental and social aspects, as shown in Figure 1. Such integration also requires a compatible assessment perspective, and accordingly, the conventional life cycle analysis (LCA) is upgraded with the TBL principle to account for the environmental and social along with the economic aspect. Such an upgrade is known as life cycle sustainability, as shown in Figure 1. LCA is a concept which traces the environmental impact of any product from its raw material state until its final disposal [19]. This is known as the "Cradle to Grave" concept. However, such a concept shows high maturity; it cannot assess the economic and social aspects. Therefore, another two life cycle assessment approaches have been introduced, which are the life cycle cost (LCC) and the social life cycle assessment (LCSA) [20]. 


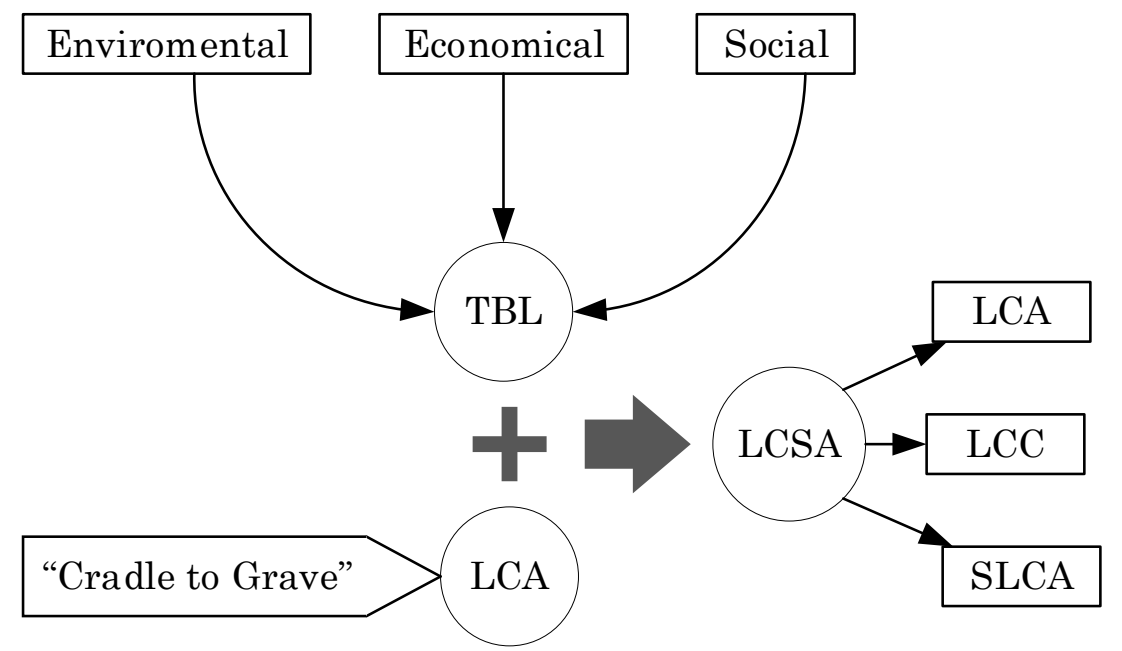

Figure 1. Combined life cycle sustainability assessment.

The LCC focuses on the economic aspects of the product throughout its life cycle. It can be divided into conventional (internal costs), environmental, and social LCC. On the other hand, the LCSA assesses the product's impact on workers, consumers, local communities, and the society. The LCSA offers a promising potential to evaluate the three aspects of the TBL, but it still suffers from the lack of clear definition for the TBL indicators. This is especially true in the case of the social and economic aspects since they show lower maturity compared to the environmental once [21]. Therefore, much work is focused on overcoming the shadowy definition of TBL aspects in general and specifically the social and economic ones. A previous work [22] conducted a systematic literature review to identify a comprehensive set of key performance indicators (KPIs) that can help to develop performance strategies in terms of sustainability. The authors selected four mains goals to each TBL perspective and then defined indicators for all of them. Another work [23] discussed the sustainability indicators and listed different sustainability sets that were used in various industries such as Ford Product Sustainability Index (Ford PSI), the 2005 Environmental Sustainability Indicators (ESI), the Global Report Initiative (GRI), and the United Nations Indicators of Sustainable Development (UN-CSD). Table 1 shows some examples of indicators that can be used for environmental, social, and economic dimensions.

Table 1. Sustainable KPI (key performance indicators) perspectives.

\begin{tabular}{cc}
\hline Sustainability Dimension & KPIs \\
Environmental & $\begin{array}{c}\text { Emission of greenhouse gas rate, carbon footprint rate, \% of waste } \\
\text { generated per thousand products units, \% of reusable/recycled material, } \\
\text { energy used per thousand of products, total consumption of water, } \\
\text { renewable energy rate, sustainable water use rate. }\end{array}$ \\
Social & $\begin{array}{c}\text { Employer satisfaction rate, number of training hours per employee, } \\
\text { health and safety rate, diversity rate, equality rate, total expenses for } \\
\text { social initiatives }\end{array}$ \\
\hline Economic & $\begin{array}{c}\text { \% of income for recycling programs, investment in technology rate, \% of } \\
\text { production sites with an environmental certificate. }\end{array}$ \\
\hline
\end{tabular}

Saad et al. [23] have developed a general framework for the sustainability assessment of manufacturing processes using quantitative and qualitative indicators for each aspect of the TBL. They were able to create indicators for each aspect and determine interactions and weights for all of them, allowing a holistic approach to the problem. A multicriteria decision-making method was used to account for the interaction among different indicators and determine scores to rank the different alternative processes and choose the best one. All these indicators intend to measure the three aspects 
of TBL quantitively. Moreover, this cannot be achieved without understanding the necessary elements to define the sustainable manufacturing concept. As shown in Figure 2, design, engagement, control, and support are the primary elements for establishing such a concept. Therefore, the challenge in the sustainability assessment is all about finding indicators that can provide an accurate representation of these elements.

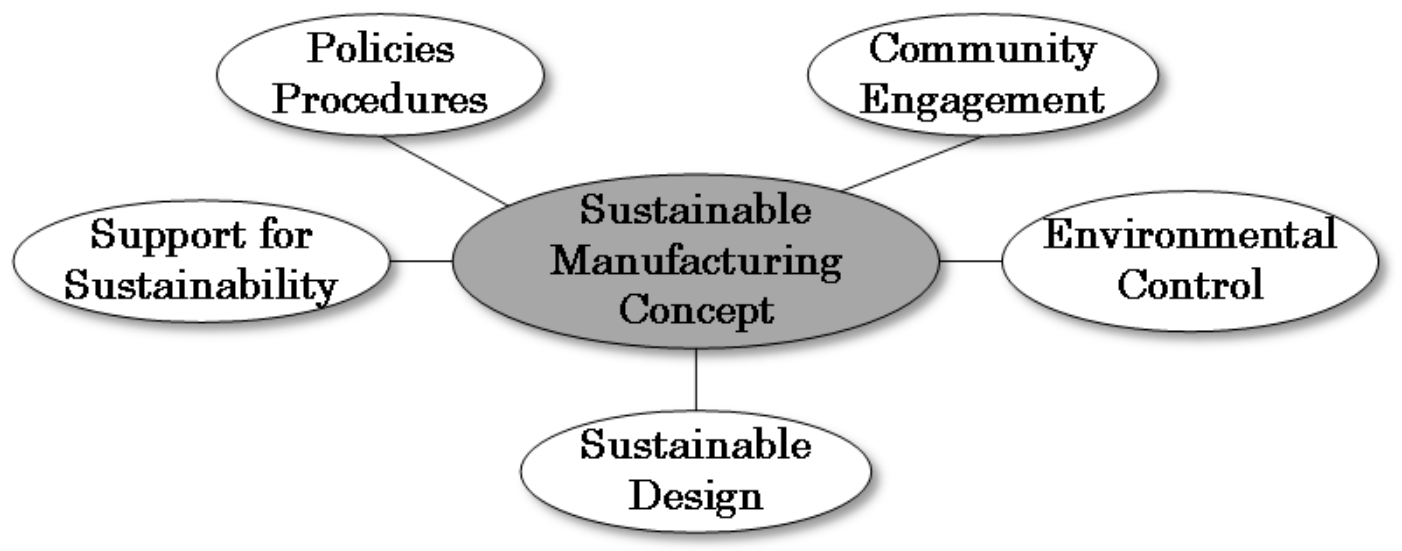

Figure 2. Sustainable manufacturing concepts: keys and aspects.

The opportunities for applying the sustainable manufacturing approach can be reflected in different aspects. These aspects include energy consumption, costs, waste management, environmental impact, health, and safety, as can be seen in Figure 3. All mentioned aspects are related to the three directions of sustainable manufacturing discussed in the open literature, including social, economic, and environmental aspects $[24,25]$. It should be stated that the interaction between these aspects is importantly necessary for terms of human activities, natural resources usage, as well as environmental indicators. Figure 4 shows the interactional concept between social, economic, and ecological directions. The socio-economic system is pressured by society to improve continuously. However, the community needs to understand how its activities can affect the environmental system. Thus, the required measures to minimize its impact on the environment are followed while complying with state regulations. This kind of interaction can effectively pave the road to accomplish significant steps towards the sustainable manufacturing concept.

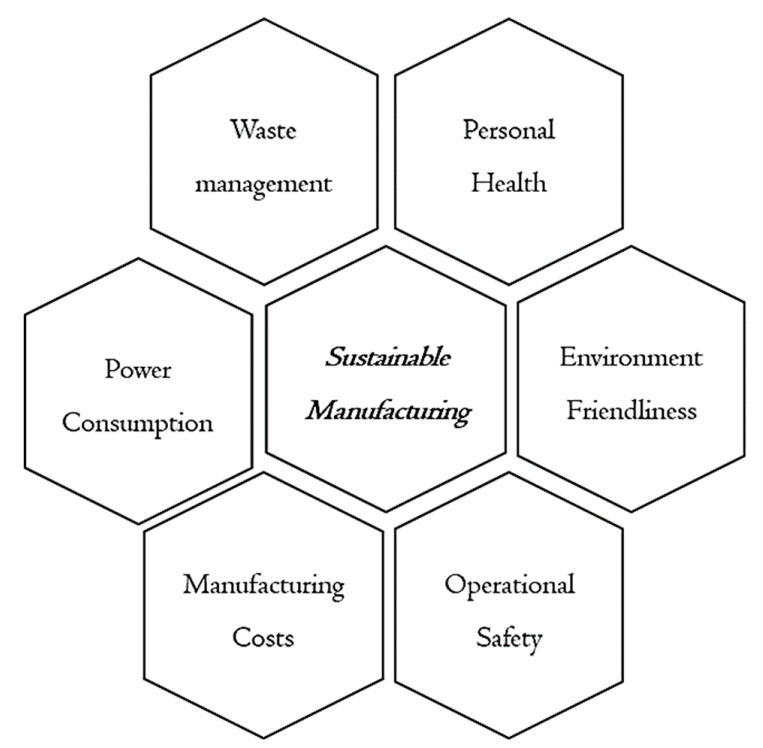

Figure 3. Sustainable manufacturing aspects. 


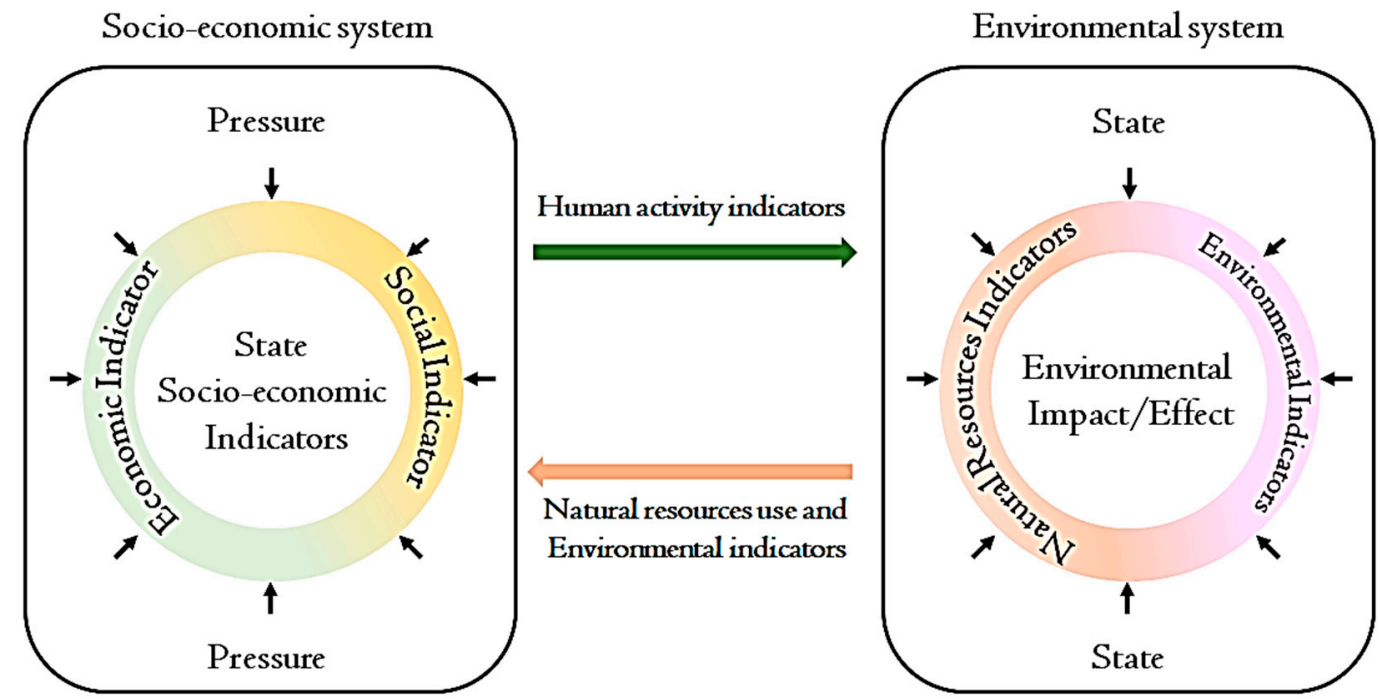

Figure 4. The interactional concept between social, economic, and environmental directions.

In order to address the required functions for the sustainable manufacturing aspects and directions, it is vital to understand the "design for sustainable manufacturing" fully. The "design for sustainable manufacturing" lies in four main stages which are manufacturing, use, inverse manufacturing, as well as inverse use [26]. These stages are connected to achieving a reliable and adaptive process or system. Such a process or system can present and understand the functionality of each element in the system, process, and product scales. Figure 5 shows a schematic to represent the concept of "design for sustainable manufacturing".

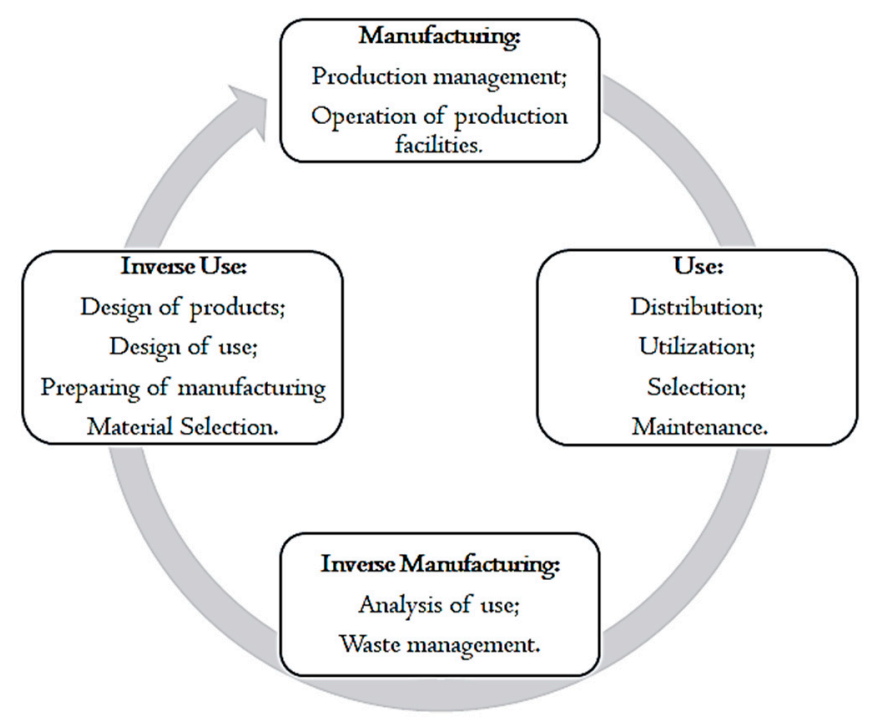

Figure 5. Elements of "design for sustainable manufacturing" concept [2,26].

It should be clarified that the "sustainable manufacturing" concept cannot be realized by focusing solely on the "design for sustainable manufacturing" direction. Thus, constructing an integrated sustainable system that covers the process, product, and system levels are required. The system should include different directions such as design for functionality, design for environmental impact, design for "6R", design for continuous improvement, design for social impact, and design for the economy. Figure 6 shows a schematic to illustrate the idea of integrated sustainability. The proper implementation of such an integrated approach can lead to and accomplish various benefits, for example, reduce consumed energy, develop new and renewable resources, eliminate toxic and severe 
health issues, improve the durability of products, achieve an effective waste management system, and improve the overall quality of the process. However, a reliable guideline should be defined to implement and design the integrated system in Figure 6. A series of steps and actions are defined to achieve the required target. These steps include developing smart-work practice, improving process optimization capabilities, offering new technologies, and focusing on the "design for sustainable production" approach.

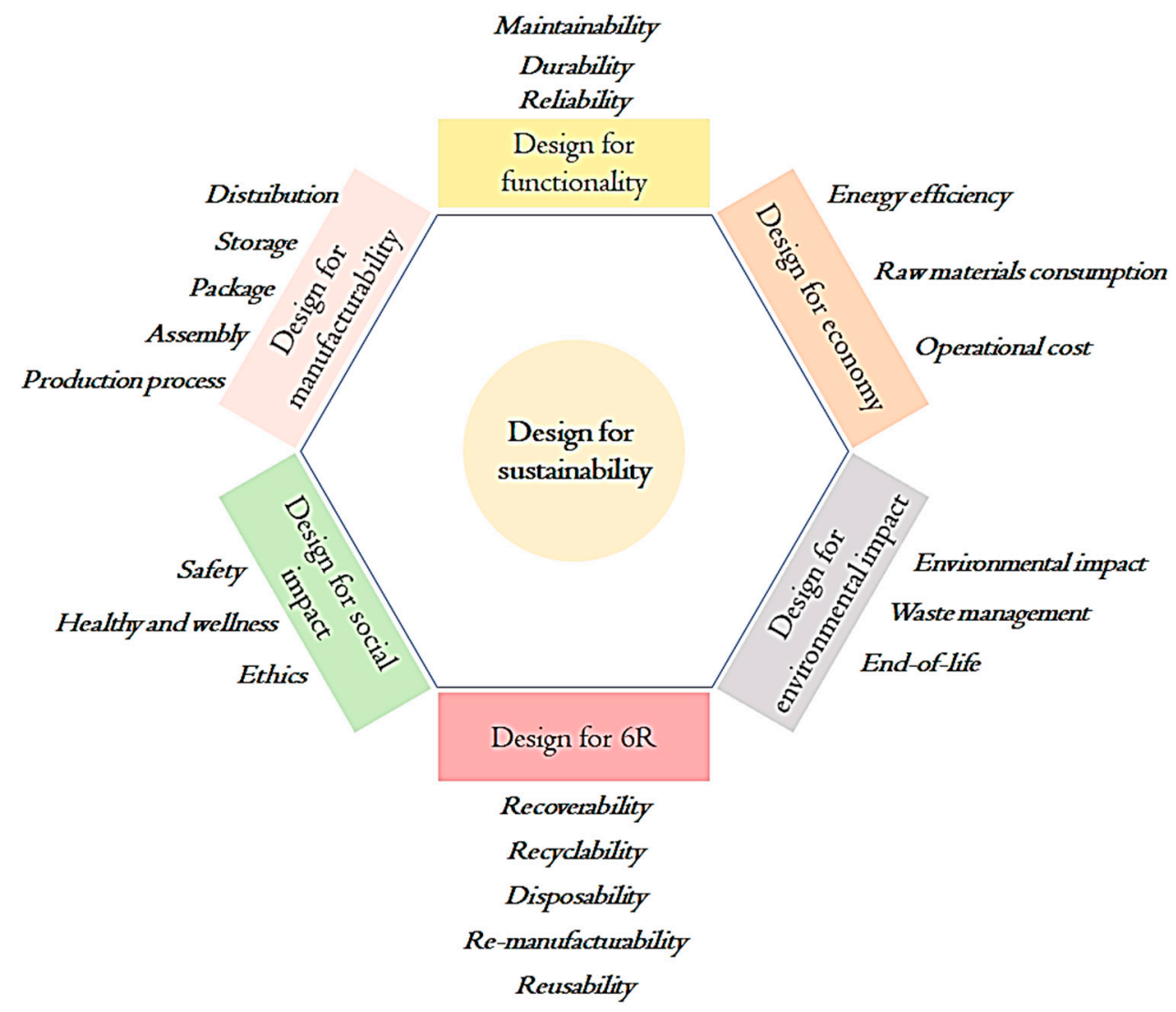

Figure 6. Design for the integrated sustainable system [27].

The next section discusses the possibility of constructing an integrated approach covering both sustainable and smart manufacturing concepts. Furthermore, this section shows how the accurate identification of sustainable manufacturing concepts and benefits is crucial to pave the road for establishing the integrated concept.

\section{Sustainable-Smart Manufacturing Approach: Industry 4.0 and Sustainability Aspects}

While our society is promoting exponential technology growth, human activities and many resources (e.g., energy, materials, water) are increasingly resulting in climate change. The modern industry is facing two significant changes that will affect all perspectives of consumption and production of the 21st century, the fourth industrial revolution, and the implementation of the sustainable manufacturing approach. The fourth industrial revolution, also known as industry 4.0, is expected to transform not only the industrial production but also the whole society. Historically, society has experienced four major industrial transformations, as shown in Figure 7. This starts with the utilization of steam power and mechanical mechanisms in production in 1784, which represents the first industrial revolution. The second industrial revolution was realized when the concept of mass production and assembly lines was adopted in different industries, for example, Henry Ford, in 1870. The third industrial revolution focused on automation and IT with the introduction of PLC and robotics in a variety of manufacturing stages in 1969. Currently, and since 2001, the industry is 
experiencing the fourth industrial revolution. This revolution is based on emergent technologies such as Big Data Analytics and the Internet of Things (IoT), enabling the development of an intelligent network that permeates all production stages and completely changes the relationship between companies and society.

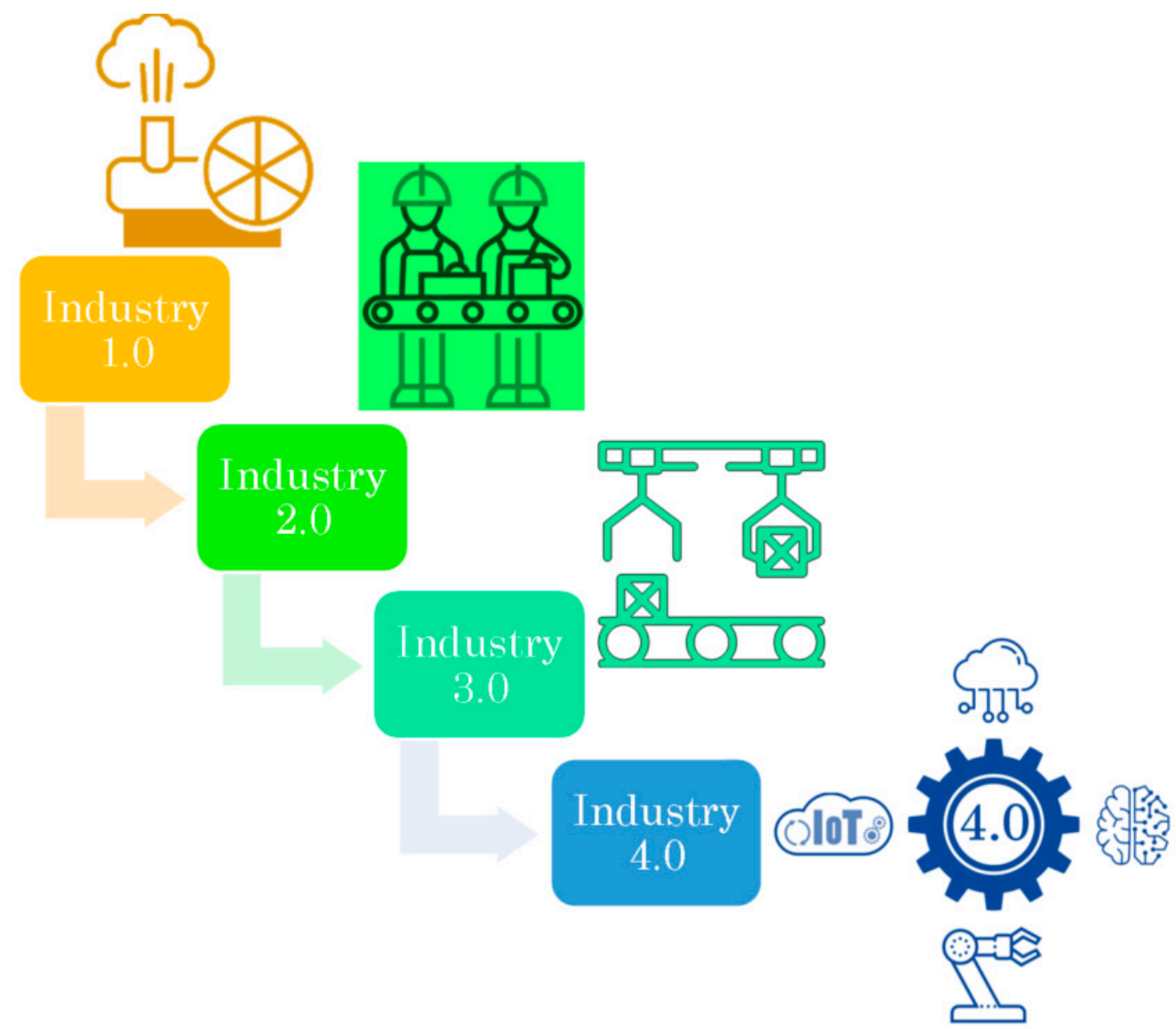

Figure 7. Industrial revolutions.

This new interlinked and holistic approach of manufacturing connects machines to the network and promotes secure real-time communication between departments, companies, and customers. Such a connection will allow devices and machines to prioritize production order, task optimization, and maintenance requirement to facilitate flexible manufacturing. In factory 4.0, machinery and processes are networked for the collection, exchange, and analysis of data in order to predict future behaviors and identify optimal solutions to possible problems. This network also allows machines to communicate and even make minor decisions without human intervention. Such networking is known as interoperability and can be categorized into three general forms: vertical, horizontal, and end to end integration [28], as shown in Figure 8. In horizontal integration, connections are established between different companies and corporations to share and exchange finance and material information. This assures new updated business models can be established. While in vertical integration, the connection is established between different subsystems within the same corporation, including sensors, actuators control, management, manufacturing, and planning. This will add flexibility to the manufacturing system by allowing smart machines to act like a self-organized system. Finally, in end-to-end integration, a link is made between a different product-oriented process throughout the product life cycle, starting from customer needs and product design to product maintenance and recycling. This integration can lead to investigating and predicting the interaction effect between these processes, enabling product customization to serve better different purposes at the different stages during its life cycle. 


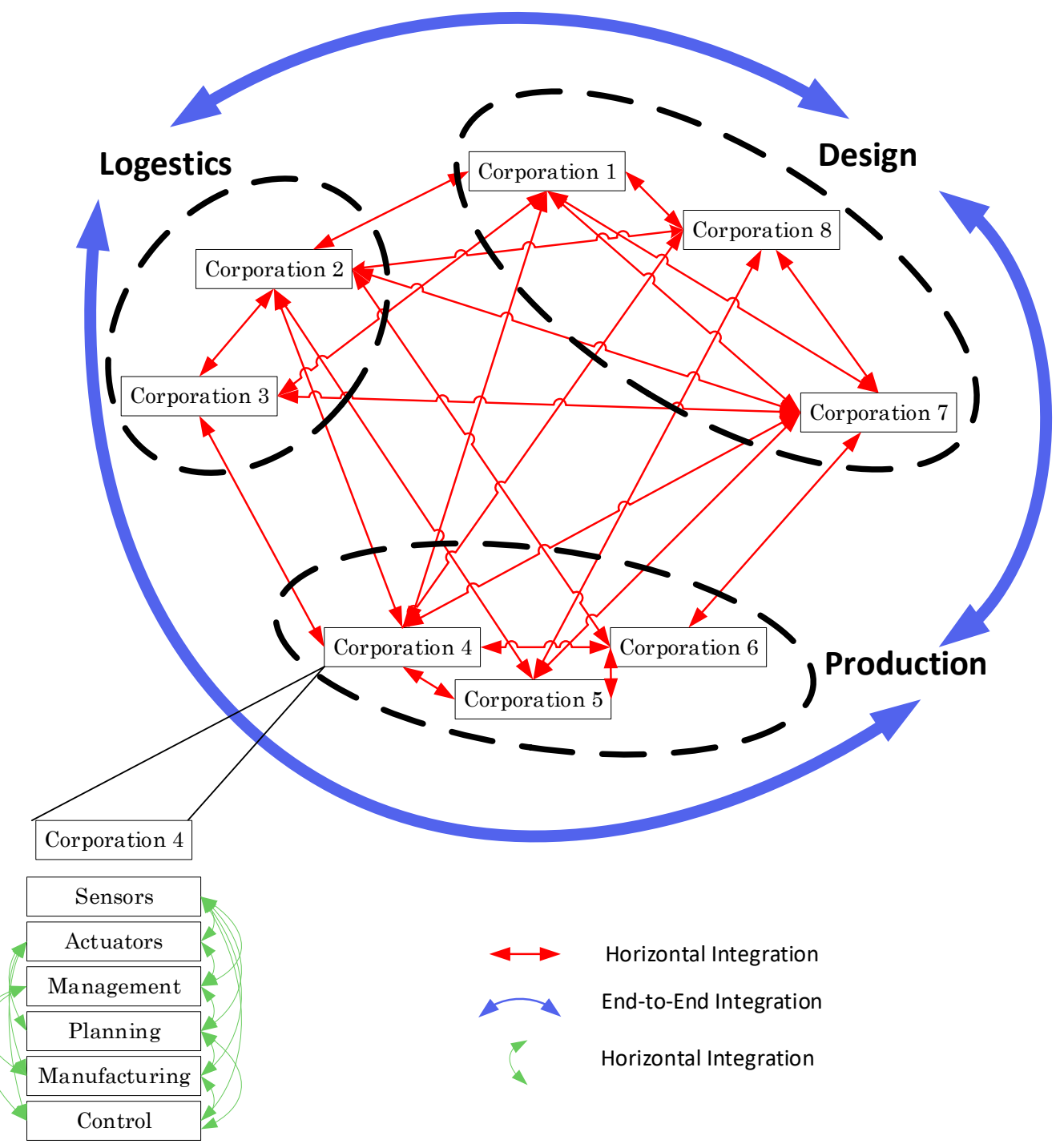

Figure 8. Interoperability in factory 4.0 [28].

McKinsey pointed out that industry 4.0 implementations have the potential to generate a value worth efficiency improvement of $15 \%$ to $20 \%$ [29]. This potential is only possible due to the added features in the smart industry compared to the conventional ones, as shown in Table 2 [28]. These added features allow the factory to be more flexible and increase its adaptation ability to different product needs without any human intervention. The machines can negotiate and interact to reconfigure for the dynamic nature of the production. This is crucial to cover the demands of different products from the same production line. This is particularly important in the last few years, as the trend has been shifted from the classical mass production to individual customer-driven products, which necessitate the ability of the same production line to create different products. This is the distinctive core objective of the smart factory. Because of the enormous potential of industry 4.0, the number of works discussing its application is rapidly growing. A wide range of applications is being developed in many different areas, e.g., process and planning, transport and logistics, supply chain, health and safety, product design, and maintenance [30]. 
Table 2. Smart and traditional factories [28].

\begin{tabular}{cc}
\hline Smart factory & Traditional factory \\
\hline Diverse Resources & Limited Fixed Resources \\
Dynamic Routing & Fixed Routing \\
Comprehensive connection & Shop Floor Control Network \\
Deep Convergence & Separated Layers \\
Self-Organized & Independent Control \\
Big Data & Isolated Information \\
\hline
\end{tabular}

Although industry 4.0 is arising during the period when attention to sustainability and sustainable development has reached its top, the majority of research works have been focused on the technical perspective. Only a few of these studies consider the impacts of this transformation in economic, ecological, and social achievements [31], which are the main pillars of sustainable manufacturing. Industry 4.0 represents an excellent opportunity to boost sustainable manufacturing by promoting a mutual concept called Source System Service (3S) route [32]. The first $S$ in this concept refers to achieving the sustainability objectives through utilizing sources that are environmentally friendly, abundant, and locally available (e.g., renewables). Then the second $S$ brings attention to optimizing the system by improving resource utilization (renewables or not). This can be realized by increasing system efficiency, multigeneration, or waste recovery. Finally, the last $\mathrm{S}$ focuses on recycling and minimizing waste and irreversibility. Figure 9 shows the impact and potential gain of adopting the $3 S$ concept on a given process. Even though industry 4.0 can contribute to the three steps, its main contribution is most significant in the system step. This is because factory 4.0 is focusing on improving system efficiency by utilizing new technologies in the manufacturing process. The improvement in system efficiency will lead to less waste and fewer losses without scarifying the production rate. Thus, it will also help in reducing resource consumption. The combined effect of fewer losses, less waste, and resource depletion are vital aspects to satisfy the three sustainability pillars (economical, environmental, and social). In the next section, the influence of factory 4.0 on these three pillars is discussed thoroughly.

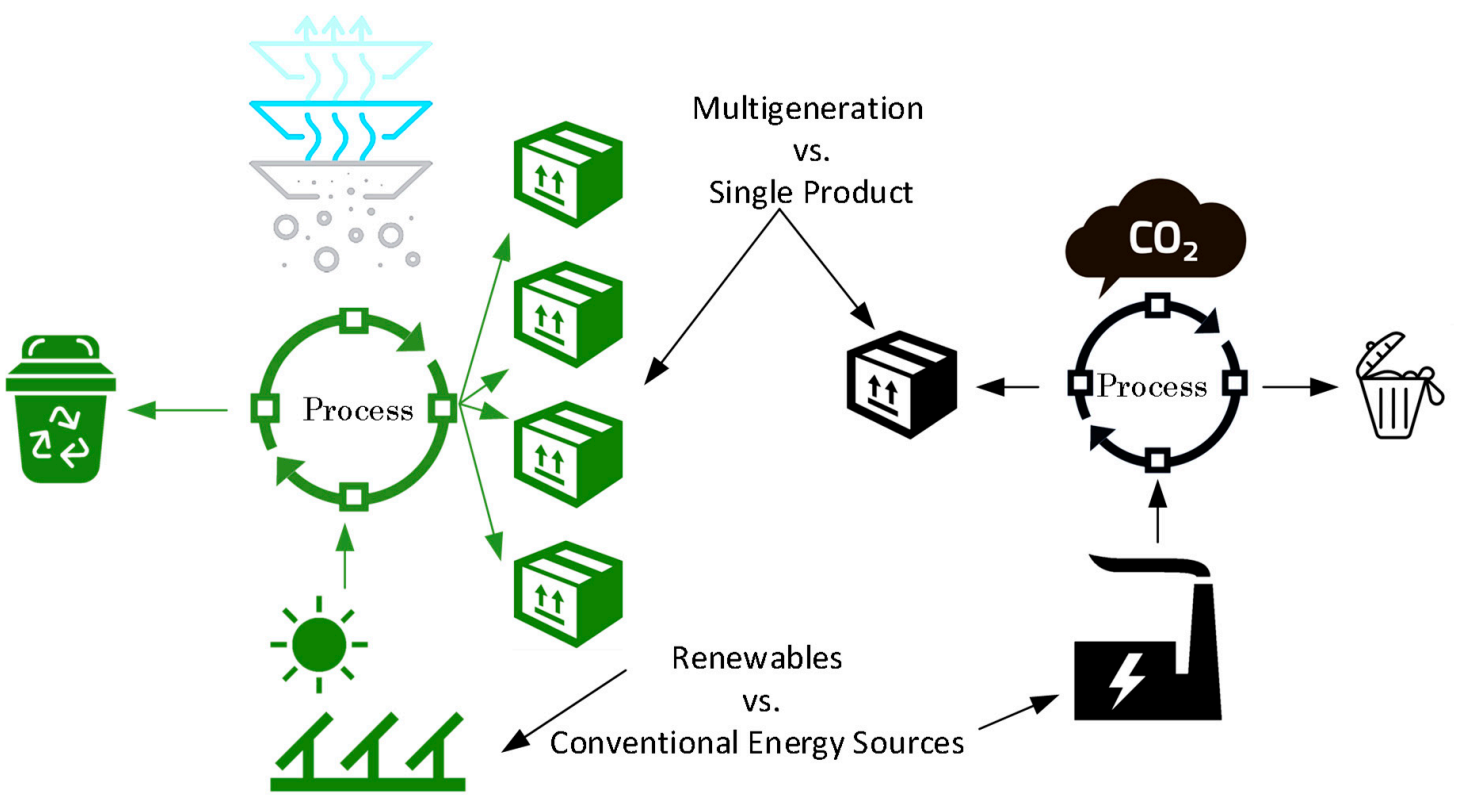

Figure 9. Progress toward sustainability through the 35 route [32].

Considering industry 4.0 is shaping the future of industry and manufacturing, it is essential to understand how it can contribute to sustainable development. In the past, the term sustainable development (i.e., traditional concept) was mainly an environmentally oriented definition; however, 
nowadays, sustainable development effectively includes three dimensions: environmental, social, and economic [33]. Thus, achieving sustainable and smart development is required in order to build a society with the appropriate equilibrium that is shaped between the two perspectives (i.e., sustainability and industry 4.0). In a previous work [34], an attempt has been done to summarize the positive impact on sustainability triple bottom line concept from applying the concepts of factory 4.0, as shown in Figure 10. They also pointed out that the effect of factory 4.0 on the sustainability TBL concept line is interactive in its nature, as shown in Figure 11. Such interaction indicates that implementing factory 4.0 features can lead to simultaneous enhancement in TBL aspects. The next part provides an in-depth analysis of the influence of factory 4.0 on each of these sustainability aspects.

Factory 4.0 Feature

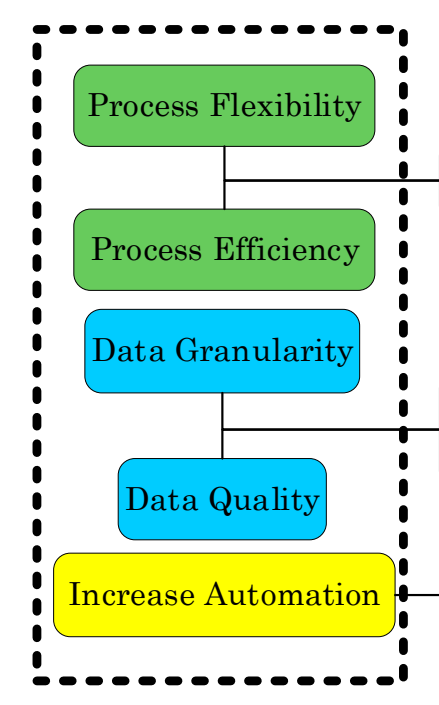

Impact on SustainabilityTBL

Figure 10. Factory 4.0 contribution to sustainability with the triple bottom line (TBL) concept [34].

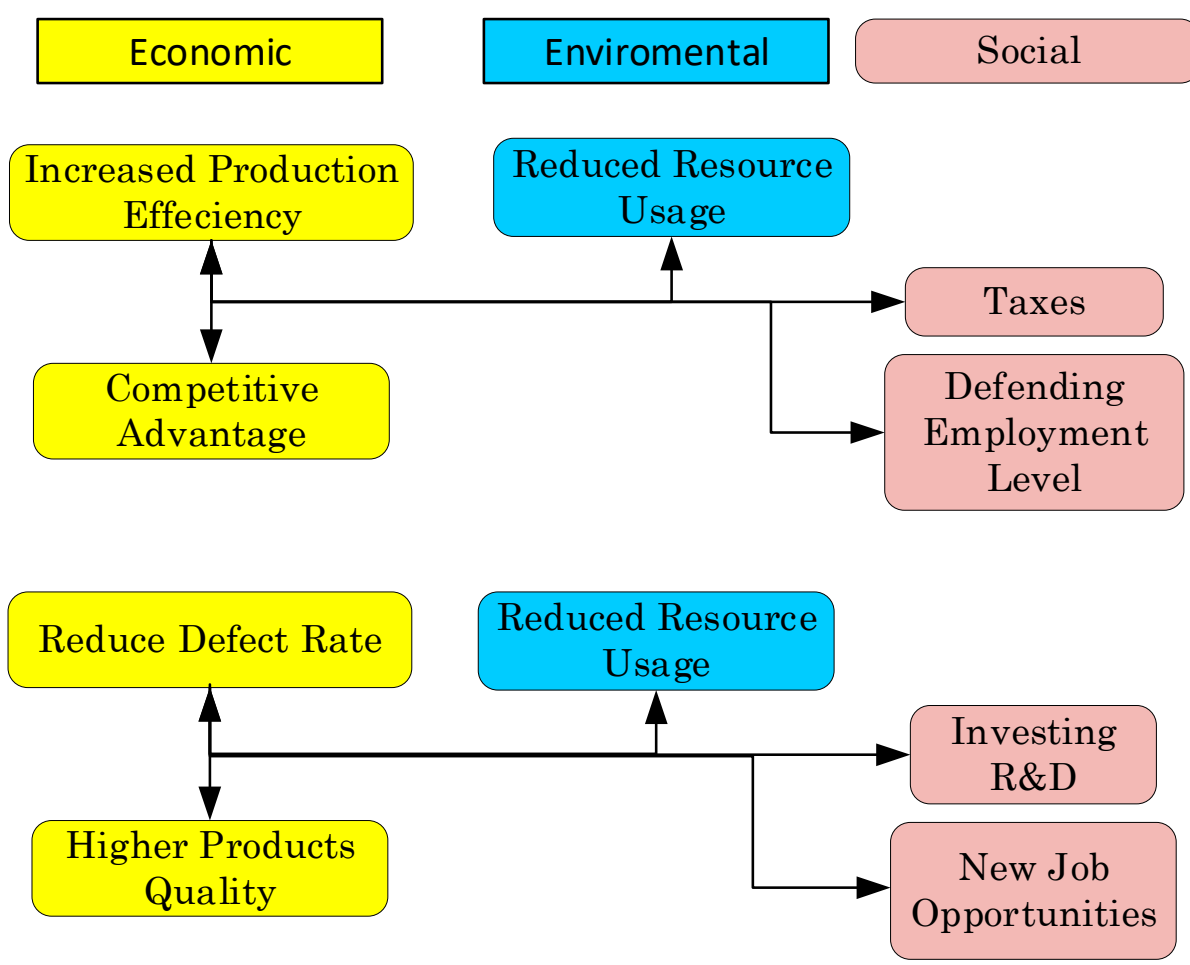

Figure 11. Interactive benefits in TBL concept due to factory 4.0 implementation [34]. 
Studying the impact of industry 4.0 on the three sustainability directions is the first step to evaluate the harmony between industry 4.0 and sustainability. Starting with the economic direction, implementing a factory will indeed improve the overall process and product performance, quality, and flexibility, although at the same time, it will require a considerable capital investment compared to the conventional one. However, at the same time, the operational and running cost will be in favor of industry 4.0 because of its diverse production capabilities. In addition, with the increasing demand for this new technology, it can be expected that it will experience a drop in the required capital investment cost. This indicates that, indeed, following factory 4.0 will promote the economic direction of sustainability. The next direction to be investigated is the environmental direction.

From an environmental point of view, applying the factory 4.0 concept cuts both ways, since its implementation will indeed improve the process impact on the environment by reducing resource usage and waste. Nevertheless, new technologies associated with factory 4.0 may lead to additional environmental liability. Further liability is a consequence of the material required for electrical devices. These materials are sometimes scarce and may require intensive extraction and processing efforts, which may negate the environmental advantage of factory 4.0. On the other hand, the utilization of factory 4.0 will, at the same time, assure dynamic interconnection between energy providers, manufacturers, and market demand. This will lead to better energy management, leading to less frequent energy overproduction or shortage. It can be argued that this will equilibrate the additional environmental liability due to the new required technologies. In addition, improving the process efficiency does not only improve the process economics but also requires fewer resources. Besides, the contribution of renewable energy to factory 4.0 helps to promote clean energy source usage. In a previous work [35], an attempt has been performed to outline eleven critical success factors (csf) that should be fulfilled in order to achieve harmony between factory 4.0 and environmental sustainability, as shown in Figure 12.

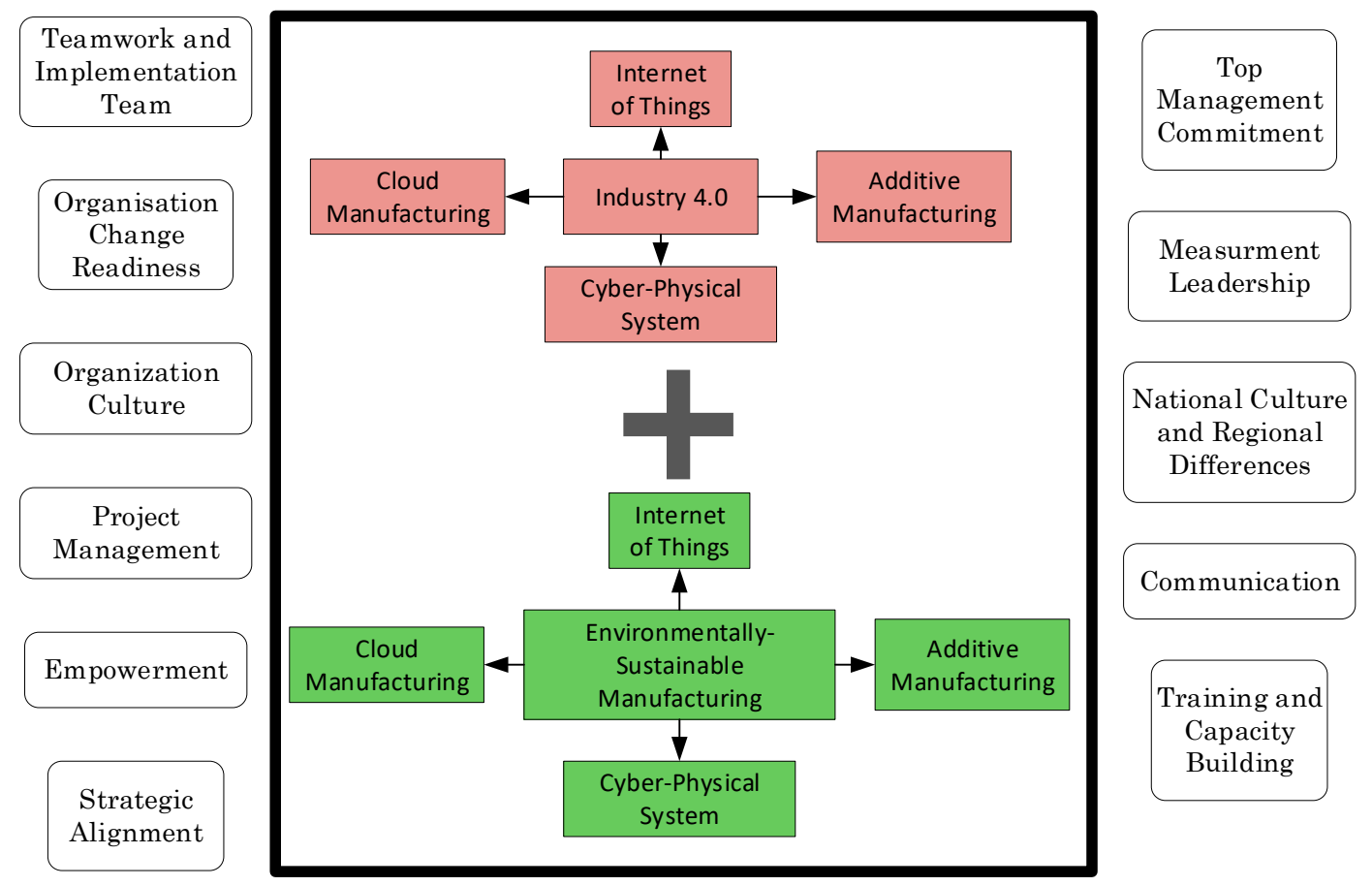

Figure 12. The critical success factors for achieving factory 4.0 and environmental sustainability harmony [35].

Finally, the last sustainability direction to check is the social direction. The idea of machines taking over human jobs emerged a long time ago. This is due to the elimination of the need for humans to do systematic routine tasks (Blue-collar jobs). Primarily, factory 4.0 is based on machines that can communicate and negotiate to make decisions without human intervention. However, at the same 
time, this will open the way and increase the demand for new jobs where humans are focused on designing, developing, and maintaining this network of machines. This will push society towards better education and training for individuals [36]. Besides, implementing factory 4.0 technologies will offer workers better and safer working conditions. In a previous work [37], a four-dimension theoretical framework has been developed to describe the dynamic nature of career sustainability in industrial innovation. Figure 13 shows the pillars of the career's sustainability model. Resourceful indicates that workers should continuously adapt to the new restrictions imposed on job options due to the industrial innovation and work on broadening their options in the long term by continually learning. Renewability is concerned with the ability of workers to upgrade their abilities to perform new tasks and have continuous education. The integrative aspect is related to how workers deal with information from diverse sources related to various fields. Workers should be able to make sense of this information and learn how to utilize it to maintain a career. Finally, resourceful, in Figure 13, implies that the workers should be capable of pursuing long-term, free of risk, and stable jobs. This will allow them to maintain a high standard of life. This can be achieved if workers manage to have access to different resources and extra income.

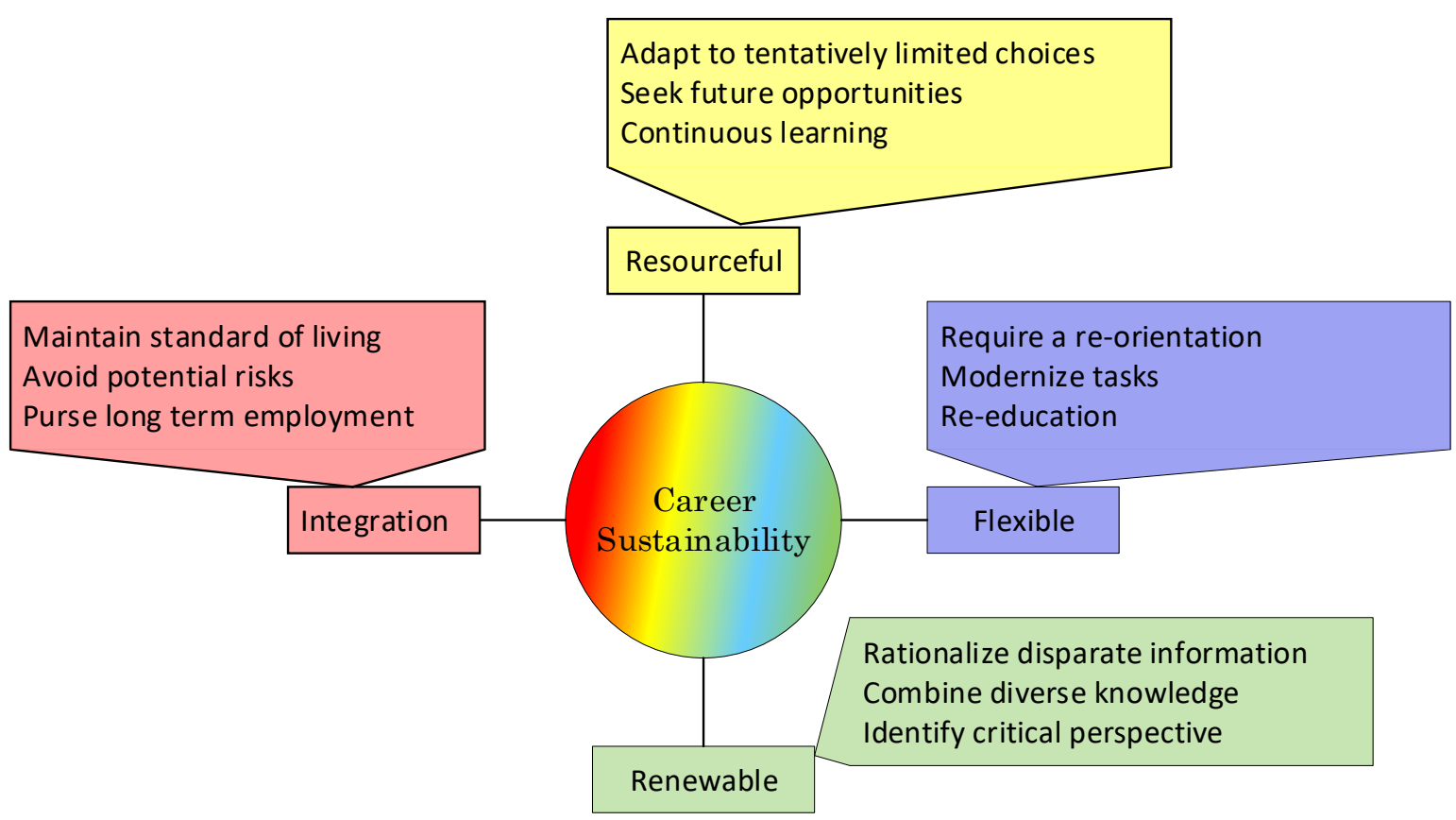

Figure 13. Four dimensions of career sustainability in industrial innovation [35].

The challenges facing industry 4.0 in the social direction and career sustainability pave the road for a new concept of industry 5.0 [38]. The main difference between factory 5.0 and factory 4.0 is the vision regarding interactions between human, cyber, and physical (machines) systems. The human and physical systems as a composite system emerged since the second industrial revolution. However, due to continuous technological leaps, cyber systems have become a crucial integrated part of this composite system, forming what is known as human cyber-physical systems (HCPSs). In such a system, the cyber system allows the machine to contribute to controlling and decision making (factory 3.0) or even more advanced intelligent control and decision making (factory 4.0) [39]. One example is the cyber-physical discrete manufacturing network developed by Gacia and his coworkers [40]. In their work, they presented an operating system for cyber-physical manufacturing (OSCM) and a paired network operations administration and monitoring (NOAM) software. Such technologies are able to improve communication and connection between manufacturers and designers, resulting in more profitable and sustainable production plans. The proposed model and solution algorithm were applied to a case study based on a network of discrete manufacturers in Illinois and Wisconsin. 
The approach was able to identify production model plans with different greenhouse gas emissions and the profit/losses associated with each of them, showing the trade-off among the objectives. However, HCPSs show great potential in increasing production efficiency and quality, and it is still argued that factory 4.0 will lead to shrinking the human workforce, thus lowering job opportunities and increasing unemployment. This may form a resistance against adopting factory 4.0. However, a newer version of HCPS (factory 5.0) is emerging, and it represents a potential solution to this problem [41]. In this new concept, machines work hand in hand with humans, observing them and learning from them in a way very similar to an apprentice. In this new concept, machines are complementing humans and not replacing them, which is the only solution to offer when factory 4.0 is resisted by labor unions and politicians due to labor career sustainability problems. A schematic summarizes the challenges and opportunities associated with industry 4.0 in Figure 14.

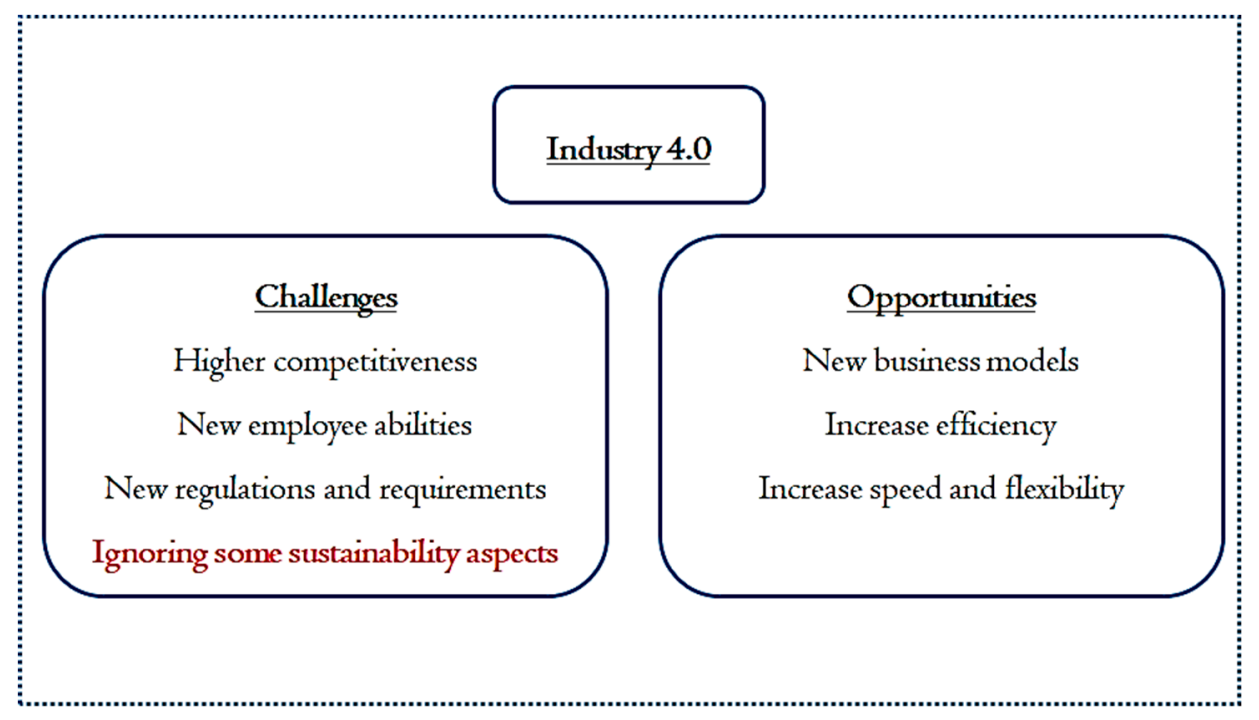

Figure 14. The opportunities and challenges associated with industry 4.0.

It can be seen that with careful and calculated implementation, integration between factory 4.0 and sustainability perspectives could guarantee to sustain and expand economic growth, customer relationships, the value of goods and facilities, employee safety and well-being, and environmental stewardship [1]. Thus, there is pressure to integrate both perspectives to end-up with a sustainable and smart business model that suits the exceptions of both external and internal agents. Figure 15 shows a schematic of the integrated sustainable and smart business model. Proper implementation of this model could lead to increasing overall profit, meeting governmental regulations, and achieving customer expectations and employee life quality through using the following elements:

- decentralized management;

- advanced technologies for better environmental impact; and

- promising energy management through information transparency and technical assistance of industry 4.0 approach. 


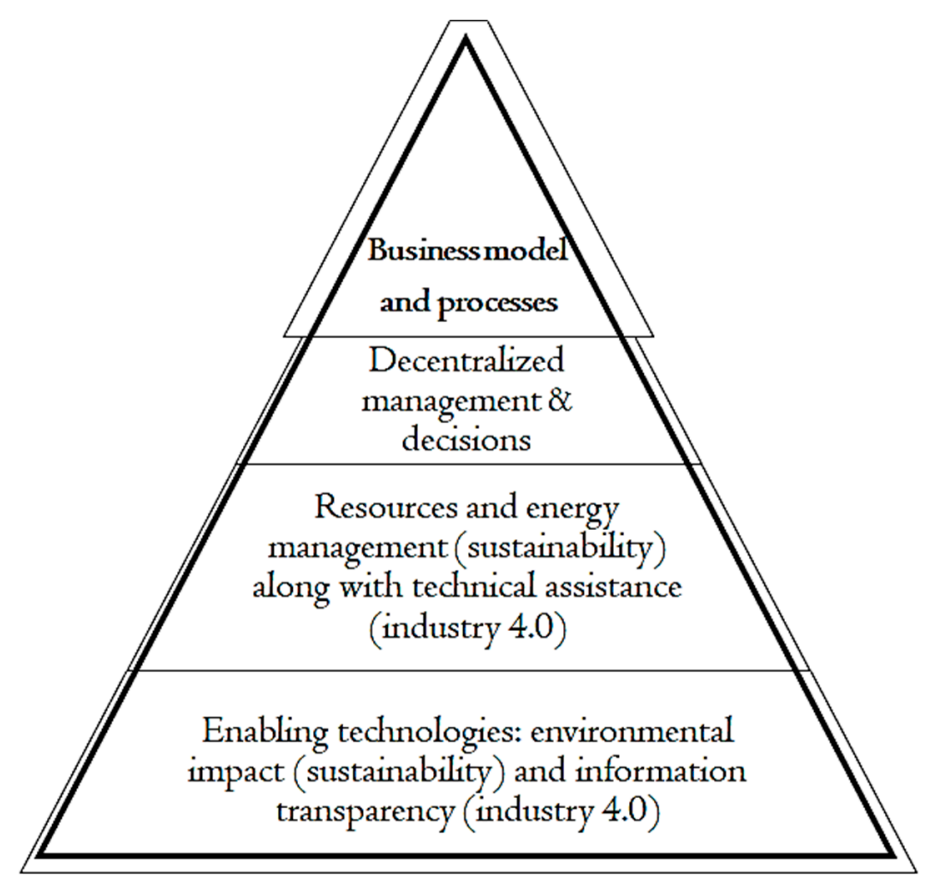

Figure 15. The elements of the smart and sustainable business model.

Finally, the integrated smart and sustainable business model should be founded on specific policies that attempt to improve the competence to meet instant facility requirements. This way will improve the quality of the environment for future generations and the business forecasts for the manufacturing sectors in the future. The next section will discuss the challenges associated with such a proposed approach.

\section{Challenges associated with sustainable manufacturing}

The previous sections discussed the concept and opportunities related to the "sustainable manufacturing" concept and the possibility of establishing a smart and sustainable manufacturing approach. Despite the benefits that industry 4.0 technologies bring, there is a long way to go, and most companies have made little progress in implementing it. A previous study [42] discussed the challenges in the implementation of smart manufacturing and pointed out that significant challenges are related to system modeling, knowledge engineering, and human-machine symbiosis. Besides, the lack of clarity regarding the economic benefits of smart, sustainable manufacturing and the resistance to changes are barriers that need to be overcome [43]. In order to offer a step forward, it is necessary to clarify and address the challenges of a sustainably oriented industry 4.0 approach. The challenges associated with establishing a sustainable and smart manufacturing approach are outlined below.

Firstly, challenges facing smart manufacturing include the following:

- implement a big-data-driven system, and industrial data must be acquired and managed with efficiency;

- $\quad$ achieve a better division of work between humans and intelligent machines;

- address the safety, privacy, and ethical issues that may be introduced by intelligent manufacturing networks;

- a detailed and comprehensive system should be constructed to link all aspects and data together in order to achieve a decentralized management system;

- a smart chain should be developed to link between the product knowledge, the stakeholder data, as well as the decision making;

- a new skilled and trained working force is needed to apply factory 4.0 concepts effectively;

- no clear solutions for the career sustainability issues arise from machines replacing humans; 
- high capital investment is required to adopt factory 4.0 principles;

- the necessity of sophisticated and advanced technological devices for massive data storage, retrieving, processing, and analysis;

- human resistance to work with robots and accept that robots may perform higher intellectual tasks. Secondly, the challenges facing sustainable manufacturing are as follows:

- no reliable definition for sustainable manufacturing practice exists in order to develop sustainability awareness between the suppliers and customers;

- a noticeable gap between industrial and academic research in areas of sustainable and smart manufacturing;

- building an effective model to define and assess all manufacturing elements and components and investigate the interactional effects between them;

- there is a need to construct a platform that includes design, manufacturing, distribution, use, and disposal elements in a single smart-integrated model;

- no optimization guideline is existing to determine the performance of all sustainable manufacturing elements accurately;

- no standard sustainability assessment metrics indicators are globally agreed upon.

Thirdly, challenges facing sustainable smart manufacturing integration include the following:

- the existing tools and methods are not enough to establish a reliable approach for "sustainable and smart manufacturing";

- there is a need to have data-driven smart algorithms for the design for sustainable manufacturing, design for sustainable supply chain, design for the sustainable end of life, and design for life cycle assessment;

- no clear and comprehensive analysis exists to define the relationship between three levels of sustainability and industry 4.0 elements;

- the added system complexity of smart sustainable manufacturing still needs to be economically justified;

- the difficulty of integrating the new smart sustainable system with existing systems in a compatible manner;

- human nature to resist and lack of courage to adopt new drastic changes (social acceptance).

\section{Conclusions}

In modern society, manufacturing is connected to all human activities, and it is a source of products and services that are necessary for human health, safety, and well-being. Considering that manufacturing processes are responsible for the creation of essential products to the quality of human life and its importance to the global economy, it is vital to analyze it in light of sustainability. Therefore, the current study aimed to integrate sustainable smart manufacturing performance by incorporating sustainable manufacturing measures and discussing the current and future challenges that are faced by the manufacturing sector. Furthermore, there is a need to establish a framework for both practitioners and scholars when it comes to sustainable manufacturing, and many companies seem to not be mindful of the potential benefits of the sustainable manufacturing approach. In this work, a new and comprehensive study was presented and discussed to address and highlight two main aspects: the concepts and benefits/opportunities associated with the proper implementation of sustainable manufacturing and the challenges facing the current industries to establish the SSM approach. The integrated smart and sustainable business model should be founded on specific policies that attempt to improve the competence to meet instant facility requirements. This way will improve the quality of the environment for future generations and the business forecasts for the manufacturing sectors in the future. This work discusses and analyzes the opportunities and challenges related to the 
practical implementation of such a new approach. In terms of future work, a detailed model will be constructed to assess simultaneously the capabilities of both sustainability aspects and industry 4.0.

Author Contributions: Conceptualization, A.T.A., M.A., and H.H.; Formal analysis, M.A., I.T. and H.H.; Investigation, M.L. and H.H.; Methodology, M.S.S. and H.H.; Software, I.T. and M.A.; Supervision, H.H. and A.T.A. All authors have read and agreed to the published version of the manuscript.

Funding: This research was funded by Deanship of Scientific Research at King Saud University, grant number RGP-1439-020.

Acknowledgments: The authors extend their appreciation to the Deanship of Scientific Research at King Saud University for funding this work through research group No. RGP-1439-020.

Conflicts of Interest: The authors declare no conflicts of interest.

\section{References}

1. Gunasekaran, A.; Spalanzani, A. Sustainability of manufacturing and services: Investigations for research and applications. Int. J. Prod. Econ. 2012, 140, 35-47. [CrossRef]

2. Kishawy, H.A.; Hegab, H.; Saad, E. Design for sustainable manufacturing: Approach, implementation, and assessment. Sustainability 2018, 10, 3604. [CrossRef]

3. Rosen, M.A.; Kishawy, H.A. Sustainable Manufacturing and Design: Concepts, Practices and Needs. Sustainability 2012, 4, 154-174. [CrossRef]

4. Seliger, G. Sustainability in Manufacturing: Recovery of Resources in Product and Material Cycles; Springer: Berlin/Heidelberg, Germany, 2007. [CrossRef]

5. Ramanujan, D.; Bernstein, W.Z.; Chandrasegaran, S.K.; Ramani, K. Visual Analytics Tools for Sustainable Lifecycle Design: Current Status, Challenges, and Future Opportunities. J. Mech. Des. 2017, 139, 111415. [CrossRef]

6. Rusinko, C. Green Manufacturing: An Evaluation of Environmentally Sustainable Manufacturing Practices and Their Impact on Competitive Outcomes. IEEE Trans. Eng. Manag. 2007, 54, 445-454. [CrossRef]

7. Bi, Z. Revisiting System Paradigms from the Viewpoint of Manufacturing Sustainability. Sustainability 2011, 3, 1323-1340. [CrossRef]

8. Rosen, M. Engineering and Sustainability: Attitudes and Actions. Sustainability 2013, 5, 372-386. [CrossRef]

9. Jayal, A.D.; Badurdeen, F.; Dillon, O.W.; Jawahir, I.S. Sustainable manufacturing: Modeling and optimization challenges at the product, process and system levels. CIRP J. Manuf. Sci. Technol. 2010, 2, 144-152. [CrossRef]

10. Hauschild, M.Z.; Jeswiet, J.; Alting, L. Design for Environment-Do We Get the Focus Right? CIRP Ann. 2004, 53, 1-4. [CrossRef]

11. Schau, E.M.; Traverso, M.; Finkbeiner, M. Life cycle approach to sustainability assessment: A case study of remanufactured alternators. J. Remanuf. 2012, 2, 5. [CrossRef]

12. Schau, E.M.; Traverso, M.; Lehmann, A.; Finkbeiner, M. Life Cycle Costing in Sustainability Assessment-A Case Study of Remanufactured Alternators. Sustainability 2011, 3, 2268-2288. [CrossRef]

13. Nasr, N.; Hilton, B.; German, R. A Framework for Sustainable Production and a Strategic Approach to a Key Enabler: Remanufacturing; Springer Science and Business Media LLC: Berlin, Germany, 2011; pp. 191-196.

14. Shuaib, M.; Metta, H.; Lu, T.; Badurdeen, F.; Jawahir, I.S.; Goldsby, T. Design and Performance Evaluation of Sustainable Supply Chains: Approach and Methodologies; Springer Science and Business Media LLC: Berlin, Germany, 2011; pp. 347-352.

15. Smart Manufacturing Leadership Coalition. Implementing 21st century smart manufacturing. In Workshop Summary Report; Smart Manufacturing Leadership Coalition: Washington, DC, USA, 2011.

16. Davis, J.; Edgar, T.; Porter, J.; Bernaden, J.; Sarli, M. Smart manufacturing, manufacturing intelligence and demand-dynamic performance. Comput. Chem. Eng. 2012, 47, 145-156. [CrossRef]

17. Harland, J.; Reichelt, T.; Yao, M. Environmental sustainability in the semiconductor industry. In Proceedings of the 2008 IEEE International Symposium on Electronics and the Environment, San Francisco, CA, USA, 19-22 May 2008; pp. 1-6.

18. Haapala, K.R.; Zhao, F.; Camelio, J.A.; Sutherland, J.; Skerlos, S.J.; Dornfeld, D.A.; Jawahir, I.S.; Clarens, A.F.; Rickli, J.L. A Review of Engineering Research in Sustainable Manufacturing. J. Manuf. Sci. Eng. 2013, 135, 041013. [CrossRef] 
19. Heijungs, R.; Huppes, G.; Guinée, J. Life cycle assessment and sustainability analysis of products, materials and technologies. Toward a scientific framework for sustainability life cycle analysis. Polym. Degrad. Stab. 2010, 95, 422-428. [CrossRef]

20. Klöpffer, W. Life cycle sustainability assessment of products. Int. J. Life Cycle Assess. 2008, 13, 89-95. [CrossRef]

21. Chang, Y.-J.; Neugebauer, S.; Lehmann, A.; Scheumann, R.; Finkbeiner, M. Life Cycle Sustainability Assessment Approaches for Manufacturing. Sustain. Manuf. 2017, 221-237.

22. Hristov, I.; Chirico, A. The Role of Sustainability Key Performance Indicators (KPIs) in Implementing Sustainable Strategies. Sustainability 2019, 11, 5742. [CrossRef]

23. Saad, M.H.; Nazzal, M.; Darras, B. A general framework for sustainability assessment of manufacturing processes. Ecol. Indic. 2019, 97, 211-224. [CrossRef]

24. Finkbeiner, M.; Schau, E.; Lehmann, A.; Traverso, M. Towards Life Cycle Sustainability Assessment. Sustainability 2010, 2, 3309-3322. [CrossRef]

25. Kuhlman, T.; Farrington, J. What is Sustainability? Sustainability 2010, 2, 3436-3448. [CrossRef]

26. Jovane, F.; Yoshikawa, H.; Alting, L.; Boër, C.; Westkamper, E.; Williams, D.; Tseng, M.; Seliger, G.; Paci, A. The incoming global technological and industrial revolution towards competitive sustainable manufacturing. CIRP Ann. 2008, 57, 641-659. [CrossRef]

27. Bhamra, T. Design for Sustainability; Informa UK Limited: Colchester, UK, 2016.

28. Wang, S.; Wan, J.; Li, D.; Zhang, C. Implementing Smart Factory of Industrie 4.0: An Outlook. Int. J. Distrib. Sens. Netw. 2016, 12, 3159805-3159810. [CrossRef]

29. Arnold, C.; Kiel, D.; Voigt, K.-I. How the industrial internet of things changes business models in different manufacturing industries. Int. J. Innov. Manag. 2016, 20, 1640015. [CrossRef]

30. Behrendt, A.; Odenwälder, P.; Müller, N.; Schmitz, C. Industry 4.0 Demystified—Lean's Next Level McKinsey, McKinsey Co. Available online: https://www.mckinsey.com/business-functions/operations/our-insights/ industry-4-0-demystified-leans-next-level (accessed on 9 January 2020).

31. Sarmiento, J.R.R.; Monroy, J.; Moreno, F.-A.; Galindo, C.; Bonelo, J.-M.; González-Jiménez, J. A predictive model for the maintenance of industrial machinery in the context of industry 4.0. Eng. Appl. Artif. Intell. 2020, 87, 103289. [CrossRef]

32. Dincer, I.; Acar, C. A review on clean energy solutions for better sustainability. Int. J. Energy Res. 2015, 39, 585-606. [CrossRef]

33. Garetti, M.; Taisch, M. Sustainable manufacturing: Trends and research challenges. Prod. Plan. Control. 2011, 23, 83-104. [CrossRef]

34. Braccini, A.M.; Margherita, E.G. Exploring Organizational Sustainability of Industry 4.0 under the Triple Bottom Line: The Case of a Manufacturing Company. Sustainability 2018, 11, 36. [CrossRef]

35. Jabbour, A.B.L.D.S.; Jabbour, C.J.C.; Foropon, C.; Filho, M.G. When titans meet-Can industry 4.0 revolutionise the environmentally-sustainable manufacturing wave? The role of critical success factors. Technol. Soc. Chang. 2018, 132, 18-25. [CrossRef]

36. Waibel, M.; Steenkamp, L.; Moloko, N.; Oosthuizen, G. Investigating the Effects of Smart Production Systems on Sustainability Elements. Procedia Manuf. 2017, 8, 731-737. [CrossRef]

37. Chin, T.; Li, G.; Jiao, H.; Addo, F.; Jawahar, I. Career sustainability during manufacturing innovation. Career Dev. Int. 2019, 24, 509-528. [CrossRef]

38. Nahavandi, S. Industry 5.0—A Human-Centric Solution. Sustainability 2019, 11, 4371. [CrossRef]

39. Zhou, J.; Li, P.; Zhou, Y.-H.; Wang, B.; Zang, J.; Meng, L. Toward New-Generation Intelligent Manufacturing. Engineering 2018, 4, 11-20. [CrossRef]

40. Garcia, D.J.; Mozaffar, M.; Ren, H.; Correa, J.E.; Ehmann, K.; Cao, J.; You, F. Sustainable Manufacturing With Cyber-Physical Discrete Manufacturing Networks: Overview and Modeling Framework. J. Manuf. Sci. Eng. 2018, 141, 021013. [CrossRef]

41. Demir, K.A.; Döven, G.; Sezen, B. Industry 5.0 and Human-Robot Co-working. Procedia Comput. Sci. 2019, 158, 688-695. [CrossRef] 
42. Zhou, J.; Zhou, Y.; Wang, B.; Zang, J.; Ji, Z.; Yanhong, Z.; Baicun, W.; Jiyuan, Z. Human-Cyber-Physical Systems (HCPSs) in the Context of New-Generation Intelligent Manufacturing. Engineering 2019, 5, 624-636. [CrossRef]

43. Raj, A.; Dwivedi, G.; Sharma, A.; Jabbour, A.B.L.D.S.; Rajak, S. Barriers to the adoption of industry 4.0 technologies in the manufacturing sector: An inter-country comparative perspective. Int. J. Prod. Econ. 2019, 107546. [CrossRef]

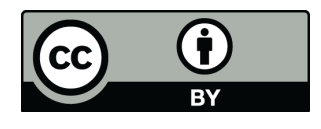

(C) 2020 by the authors. Licensee MDPI, Basel, Switzerland. This article is an open access article distributed under the terms and conditions of the Creative Commons Attribution (CC BY) license (http://creativecommons.org/licenses/by/4.0/). 